\title{
Queratoacantoma de vulva: presentación de un caso
}

\author{
Catalina Agudelo R. ${ }^{1}$, Luis René Pareja $F^{2}$, Gabriel Rendón $P^{2}$, Carlos Andrés Serna O. ${ }^{3}$ \\ ${ }^{1}$ Residente de Ginecología y Obstetricia, Universidad Pontificia Bolivariana. ${ }^{2}$ Ginecólogo Oncólogo, Instituto de \\ Cancerología, Las Américas. ${ }^{3}$ Patólogo, Clínica Las Américas. Medellín, Colombia.
}

\section{RESUMEN}

El queratoacantoma de vulva es una entidad rara que podría presentar confusión en su diagnóstico con el carcinoma bien diferenciado de células escamosas. Presentamos un caso de una paciente con diagnóstico de queratoacantoma de vulva tratada con resección quirúrgica de la lesión y su seguimiento posterior.

\section{PALABRES CLAVE: Queratoacantoma vulvar, carcinoma vulvar, células escamosas, vulva}

\section{SUMMARY}

Vulvar keratoacanthoma is a rare disease that may present confusion in diagnosis with well differentiated squamous cell carcinoma. We report one patient with vulvar keratoacanthoma, treated by resection surgery of the lesion and her outcome.

\section{KEY WORDS: Vulvar keratoacanthoma, vulvar carcinoma, squamous cell, vulva}

\section{INTRODUCCIÓN}

El queratoacantoma es un tumor de la piel, generalmente solitario, de color rosa o carne, con queratina central en forma de cúpula. Estos tumores pueden aparecer en cualquier parte del cuerpo, pero con mayor frecuencia se desarrollan en áreas expuestas al sol. Carcinógenos químicos y el virus del papiloma humano se han asociado con su etiología pero la exposición excesiva a luz solar se ha sugerido como el principal agente en la mayoría de los casos (1). El pico de incidencia es entre 50 y 69 años de edad y hay una preponderancia masculina (2). Es una neoplasia cutánea común con distintivas características clínicas e histopatológicas similares al carcinoma de células escamosas. Su curso clínico se caracteriza por una fase de rápido crecimiento, seguido por la involución espontánea. Las propiedades invasivas del epitelio escamoso pueden estar presentes en el queratoacantoma, su distinción con el carcinoma de células escamosas bien diferenciado es un diagnóstico difícil que requiere una cuidadosa evaluación $(3,4)$.

El queratoacantoma es más común en áreas con exposición al sol, y su presentación en la vulva es rara. Hasta ahora, seis casos de queratoacantoma vulvar se han reportado en la literatura (Tabla I) (5-9).

Se presenta el reporte de un caso atendido en nuestra institución luego de ser aceptado por el comité de ética médica.

\section{Caso clínico}

Mujer de 90 años de edad quien consulta por cuadro clínico de un mes de evolución de aparición de lesión en la vulva, dolorosa, de rápido crecimiento, manejada con agentes tópicos sin mejoría. Antecedente de osteoporosis en tratamiento con bifosfonato y sin otro tipo de antecedente importante.

Al examen físico se observa lesión nodular, hipopigmentada de $2 \mathrm{~cm}$ de diámetro localizada en 
tercio superior de labio mayor derecho sugestiva de neoplasia, bien delimitada, sin lesiones satélites asociadas ni adenopatías. El resto del examen ginecológico fue catalogado como normal.

Se realiza resección local ampliada en elipse de la lesión, con márgenes de $1 \mathrm{~cm}$, disección hasta alcanzar $2 \mathrm{~cm}$ de profundidad desde su base.

En el estudio anatomopatológico final confirma queratoacantoma de vulva, márgenes negativos, el menor a 0,3 cm y el mayor a más de $0,5 \mathrm{~cm}$, sin invasión linfovascular ni perineural (Figuras 1, 2 y 3).

Después del seguimiento de 11 meses, no se ha documentado evidencia de recurrencia de la lesión.

\section{DISCUSIÓN}

Se presenta el séptimo caso de un queratoacantoma vulvar en la literatura mundial (PubMed revisión de la literatura desde 1985 hasta 2014) (Tabla I).

En la literatura médica han sido reportadas 6 pacientes con queratoacantoma de la vulva, con una mediana de edad de 51,5 años, todas con lesiones únicas en la vulva, de rápida progresión, la mayoría de éstas ubicadas en los labios mayores, el tamaño de las lesiones con una mediana de 0,97 $\mathrm{cm}$, ninguna paciente con recurrencia durante el seguimiento promedio de 35,8 meses.

El queratoacantoma de vulva es muy raro, su distinción con el carcinoma escamocelular bien diferenciado es esencial, ya que las consecuencias para el tratamiento son significativas. No existe un marcador de inmunohistoquímica específico disponible en la actualidad, que permita establecer el diagnóstico diferencial, por lo que debe hacerse con los cortes rutinarios teñidos con Hematoxilina - Eosina (1).

Las lesiones tempranas se forman por invaginaciones de epitelio escamoso queratinizante, bien diferenciado y a medida que maduran muestran un cráter central lleno por un tapón de queratina. Clásicamente, en la evaluación a bajo aumento, el queratoacantoma muestra una arquitectura simétrica debido al reforzamiento de los bordes de la lesión que se sobreponen al cráter central (Figura 1); en la evaluación a mayor aumento, las células hacia el centro de los nidos se agrandan (hasta dos veces el tamaño de los queratinocitos normales), con citoplasma eosinófilo. La atipia y las mitosis son raras, no hay desmoplasia, la lesión es bien delimitada y no se extiende por debajo del nivel de las glándulas sudoríparas (Figuras 2 y 3 ).

Tabla I

QUERATOACANTOMA VULVAR. CASOS REPORTADOS EN LA LITERATURA

\begin{tabular}{|c|c|c|c|c|c|c|}
\hline Caso & Referencia & $\begin{array}{l}\text { Edad } \\
\text { (años) }\end{array}$ & Localización & Tamaño & Tratamiento & Seguimiento \\
\hline 1 & $\begin{array}{l}\text { Rhatigan RM, Nuss RC. Ke- } \\
\text { ratoacanthoma of the vulva. } \\
\text { Gynecol Oncol 1985;21:118-23. }\end{array}$ & 65 & Labio mayor derecho & $1,5 \mathrm{~cm}$ & Biopsia excisional & $\begin{array}{l}24 \text { meses sin } \\
\text { recurrencia }\end{array}$ \\
\hline 2 & $\begin{array}{l}\text { Gilbey S, et al. Vulvar kera- } \\
\text { toacanthoma. Obstet Gynecol } \\
\text { 1997; 89:848-50. }\end{array}$ & 54 & $\begin{array}{l}\text { Tercio medio de labio } \\
\text { mayor derecho }\end{array}$ & $1 \mathrm{~cm}$ & Escisión local & $\begin{array}{l}24 \text { meses sin } \\
\text { recurrencia }\end{array}$ \\
\hline 3 & $\begin{array}{l}\text { Chen W, Koenig C. Vulvar } \\
\text { keratoacanthoma: a report of } \\
\text { two cases. Int J Gynecol Pathol } \\
2004 ; 23: 284-6 \text {. }\end{array}$ & 49 & Labio mayor izquierdo & $0,8 \mathrm{~cm}$ & Biopsia excisional & $\begin{array}{l}138 \text { meses sin } \\
\text { recurrencia }\end{array}$ \\
\hline 4 & $\begin{array}{l}\text { Chen W, Koenig C. Vulvar } \\
\text { keratoacanthoma: a report of } \\
\text { two cases. Int J Gynecol Pathol } \\
\text { 2004;23:284-6. }\end{array}$ & 44 & Labio mayor izquierdo & $1 \mathrm{~cm}$ & Biopsia excisional & $\begin{array}{l}14 \text { meses sin } \\
\text { recurrencia }\end{array}$ \\
\hline 5 & $\begin{array}{l}\text { Nascimento MC, et al. Vulvar } \\
\text { keratoacanthoma. Gynec Oncol } \\
\text { 2005;97:674-6. }\end{array}$ & 79 & $\begin{array}{l}\text { Cara lateral izquierda } \\
\text { de clítoris }\end{array}$ & $0,9 \mathrm{~cm}$ & Escisión local & $\begin{array}{l}1 \text { mes sin } \\
\text { recurrencia }\end{array}$ \\
\hline 6 & $\begin{array}{l}\text { Ozkan F, et al. Vulvar ke- } \\
\text { ratoacanthoma. APMIS } \\
\text { 2006;114:562-5. }\end{array}$ & 33 & Sobre el clítoris & $1 \mathrm{~cm}$ & Biopsia excisional & $\begin{array}{l}14 \text { meses sin } \\
\text { recurrencia }\end{array}$ \\
\hline 7 & Caso reportado & 90 & Labio mayor derecho & $2 \mathrm{~cm}$ & Biopsia excisional & $\begin{array}{l}11 \text { meses sin } \\
\text { recurrencia }\end{array}$ \\
\hline
\end{tabular}




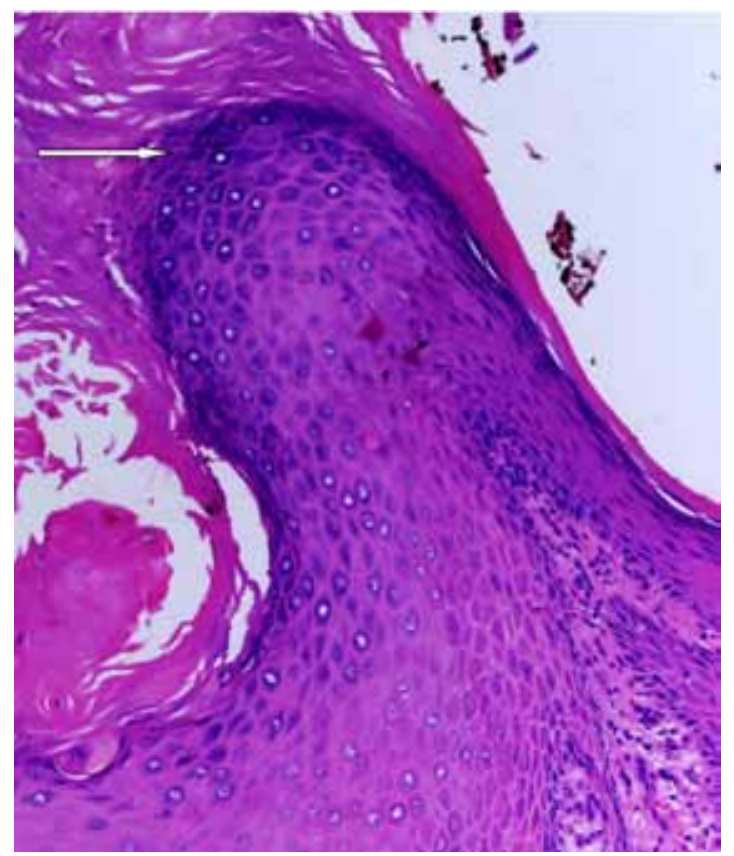

Figura 1. Hematoxilina - Eosina (100X). Márgenes de la lesión, se observa la invaginación del epitelio escamoso (flecha) formando un cráter ocupado por queratina.

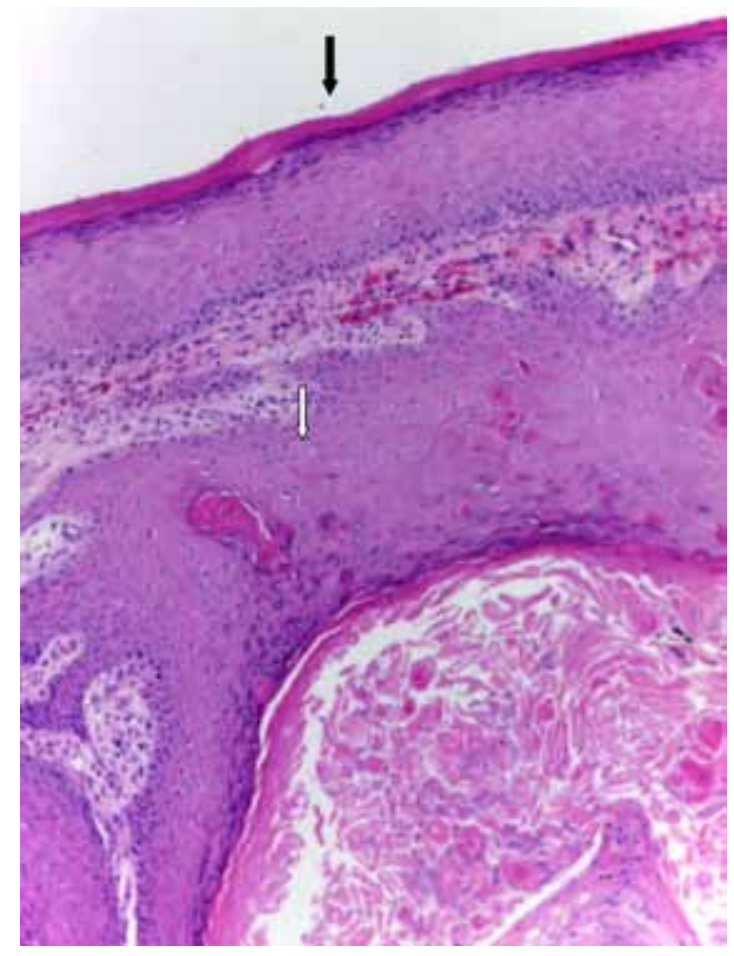

Figura 2. Hematoxilina - Eosina, (100X). Nidos irregulares de células escamosas (flecha blanca) proliferando debajo la dermis intacta (flecha negra) en el margen de la lesión.

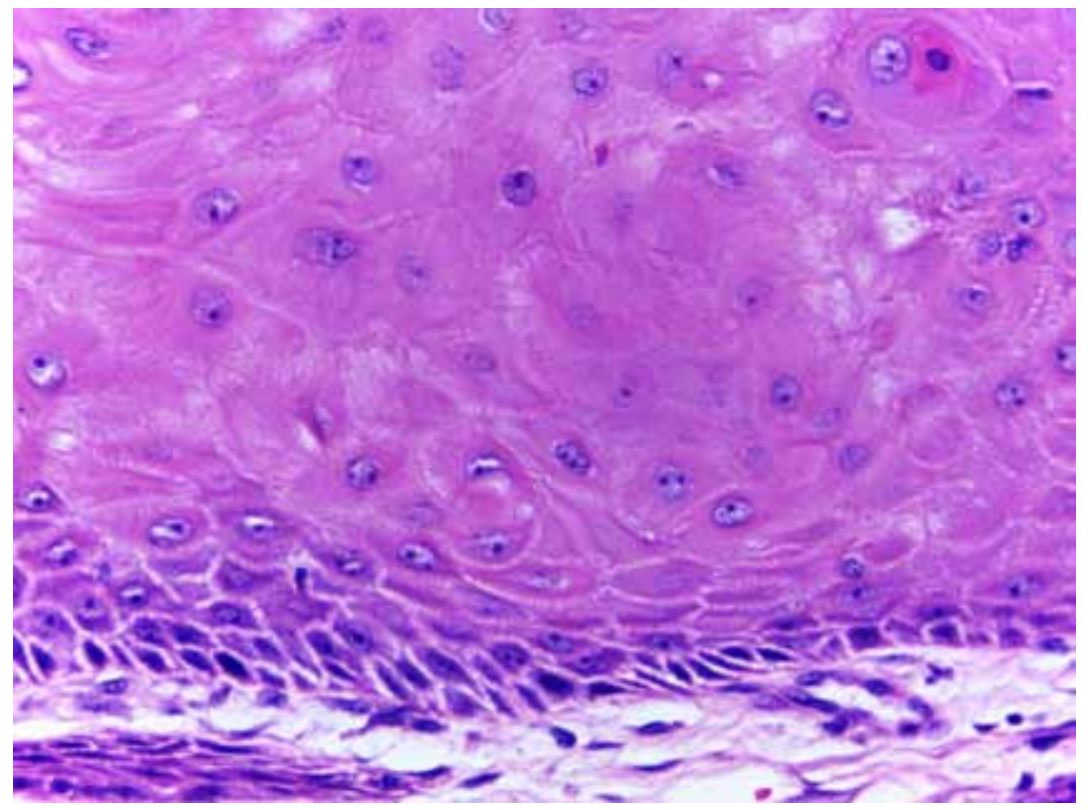

Figura 3. Hematoxilina - Eosina (400X). Queratinocitos aumentados de tamaño con citoplasma eosinófilo, sin atipia citológica o actividad mitótica. 


\section{Tabla II \\ DIFERENCIAS CLÍNICAS Y PATOLÓGICAS ENTRE QUERATOACANTOMA Y CARCINOMA DE CÉLULAS ESCAMOSAS DE LA VULVA}

\begin{tabular}{lcc}
\hline Rasgo & Queratoacantoma & Carcinoma de células escamosas \\
\hline Tasa de crecimiento & Rápido (semanas) & Lenta (meses) \\
Regresión espontánea & $\mathrm{Si}$ & No \\
Patrón de crecimiento & Cráter de queratina & Masa infiltrante irregular \\
VIN en piel adyacente & No & $\mathrm{Si}$ \\
Atipia & $+/-$ & $+\mathrm{a}+++$ \\
Actividad mitótica & Baja & $+\mathrm{a}+++$ \\
Prevalencia VPH ADN & Baja & Alta \\
\hline
\end{tabular}

VIN: neoplasia vulvar intra epitelial

El principal dilema diagnóstico es distinguirlo del carcinoma de células escamosas bien diferenciado, sobre todo en la fase temprana de crecimiento activo del queratoacantoma, antes de que el tapón central de queratina característico esté bien desarrollado. Usualmente, el carcinoma de células escamosas carece del crecimiento simétrico del queratoacantoma, presenta desmoplasia, displasia y es menos delimitado (1).

El tratamiento estándar para el queratoacantoma vulvar es la resección quirúrgica. Por ser una lesión benigna, la escisión local amplia ha demostrado ser eficaz y la recurrencia se puede esperar hasta en un $8 \%$ de las pacientes (10).

Un diagnóstico correcto puede evitar las consecuencias de una cirugía radical de la vulva, el área inguinal y la linfadectomía, tratamiento estándar del carcinoma escamo celular de la vulva (11). Las características que ayudan a distinguir queratoacantoma del carcinoma escamocelular de la vulva se presentan en la Tabla II.

\section{CONCLUSIÓN}

El diagnóstico diferencial del carcinoma escamocelular bien diferenciado de la vulva debe incluir el queratoacantoma, en particular en aquellas lesiones con una historia de rápido crecimiento y un cráter central relleno de queratina. El conocimiento de esta entidad puede ayudar a evitar un diagnóstico y tratamiento erróneos.

\section{REFERENCIAS}

1. Weedon D. Tumors of the epidermis. In: Houston MJ, editor. Skinpathology, 2nd ed. Brisbane7 Churchill Livingstone; 2002. pp 751-802.

2. Griffiths RW. Keratoacanthoma observed. Br Assoc Plast Surg 2004;57:485-501.

3. Schwartz RA. Keratoacanthoma. J Am Acad Dermatol 1994;30:1-19.

4. Schwartz RA. The keratoacanthoma: a review. J Surg Oncol 1979;12:305-17.

5. Rhatigan RM, Nuss RC. Keratoacanthoma of the vulva. GynecolOncol 1985;21:118-23.

6. Chen W, Koenig C. Vulvar keratoacanthoma: a report of two cases. Int J Gynecol Pathol 2004;23:284-6.

7. Gilbey S, Moore DH, Look KY, Sutton GP. Vulvar keratoacanthoma. Obstet Gynecol 1997;89:848-50.

8. Nascimento MC, Cominos D, Davies NJ, Obermair A. Vulvar keratoacanthoma. Gynecologic Oncology 2005;97:674-6.

9. Ozkan F, Bilgiç R, Cesur S. Vulvarkeratoacanthoma. APMIS 2006;114:562-5.

10. Weedon D. Keratoacanthoma: a personal perspective. Curr Diagn Pathol 2003;9:259-65.

11. Hsi ED, Svoboda-Newman SM, Stern RA, Nickoloff BJ, Frank TS. Detection of human papilloma virus DNA in keratoacanthomas by polymerase chain reaction. Am J Dermatopathol1997;19:10-5. 